Silveira, RB, Quadros, IP \& Silva, CLLPV (2020). Poetic itineraries: moving around the city as a driver of aesthetic experiences in art teaching. Research, Society and Development, 9(7): 1-16, e554974343.

\title{
Itinerários poéticos: o deslocamento pela cidade como propulsor de experiências estéticas no ensino de arte
}

Poetic itineraries: moving around the city as a driver of aesthetic experiences in art teaching

Itinerarios poéticos: moverse por la ciudad como motor de experiencias estéticas en la enseñanza del arte

Recebido: 08/05/2020 | Revisado: 15/05/2020 | Aceito: 17/05/2020 | Publicado: 30/05/2020

\section{Rafael Branco da Silveira}

ORCID: https://orcid.org/0000-0002-0703-2588

Instituto Federal de Educação, Ciência e Tecnologia de Mato Grosso, Brasil

E-mail: rafa_brancors@hotmail.com

Imara Pizzato Quadros

ORCID: https://orcid.org/0000-0003-2556-0293 Instituto Federal de Educação, Ciência e Tecnologia de Mato Grosso, Brasil E-mail: imara.quadros@cba.ifmt.edu.br Cláudia Lúcia Landgraf Pereira Valério da Silva ORCID: https://orcid.org/0000-0001-8222-1293 Instituto Federal de Educação, Ciência e Tecnologia de Mato Grosso, Brasil E-mail: claudia.valerio@cba.ifmt.edu.br

\section{Resumo}

A relação diacrônica entre o espaço e tempo é o vetor central desta pesquisa. A cidade não é um corpo fechado, imutável e permanente, cuja estrutura revela uma sólida constância, mas um corpo aberto, uma catarse do tempo que no seu decurso metamorfoseia-se, a partir daqueles que a ocupam, habitam e por ela circulam. Por conseguinte, as constantes transformações ou permanências na paisagem urbana da cidade refletem diretamente nas relações históricas, mnemônicas e identitárias dos habitantes com a imagem, estética e estrutura citadina. Diante destas constantes transformações no espaço-tempo, o presente artigo objetiva apresentar algumas proposições acerca de práticas pedagógicas no ensino de arte que 
se utilizem do processo de deslocamento urbano como propulsor de experiências sensíveis ao educando, capaz de despertar neste um olhar poético sobre a cidade. Para isso, o percurso metodológico traçado é de natureza qualitativa, investigando as percepções dos educandos na cidade, as quais se materializam por meio de seus registros poéticos e imagéticos. Desse modo, a abordagem fenomenológica para a compreensão dos dados pontuou que a referida prática pedagógica de deslocamento urbano possibilitou aproximar e ampliar o contato dos educandos com os diferentes espaços citadinos, incitando um olhar sensível e poético com a estética e estrutura urbana.

Palavras-chave: Arte; Ensino de arte; Arte como experiência; Deslocamento urbano.

\section{Abstract}

The diachronic relationship between space and time is the central topic of this research. The city is not a closed, immutable, and permanent body whose structure reveals a solid constancy, but an open body, a catharsis of time that in its course is metamorphosed, from those who occupy, inhabit and circulate through it. Consequently, the constant transformations or conservation in the urban landscape of the city directly reflect on the historical, mnemonic and identity relationships of the inhabitants with the image, aesthetics and city structure. In view of these constant transformations in space-time, this article aims to present some propositions about pedagogical practices in teaching art that use the process of urban displacement as a propellant of sensitive experiences to the student, capable of awakening a poetic look on the city. For this, the methodological path described is of a qualitative nature, investigating the perceptions of students in the city, materialized by their poetic and imagery records. In this way, the phenomenological approach to understand the data pointed out that the referred pedagogical practice of urban displacement made it possible to approach and expand the contact of students with the different city spaces Inciting in them a sensitive poetic look at the aesthetic and urban structure.

Keywords: Art; Art teaching; Art as experience; Urban displacement.

\section{Resumen}

La relación diacrónica entre el espacio y el tiempo es el vector central de esta investigación. La ciudad no es un cuerpo cerrado, inmutable y permanente cuya estructura revela una constancia sólida, pero es un cuerpo abierto, una catarsis del tiempo que en su curso se transforma, por quienes la ocupan, habitan y circulan a través de ella. En consecuencia, las constantes transformaciones o permanencias en el paisaje urbano de la ciudad se reflejan 
directamente en las relaciones históricas, mnemónicas y de identidad de los habitantes con la imagen, la estética y la estructura de la ciudad. En vista de estas constantes transformaciones en el espacio-tiempo, este artículo tiene como objetivo presentar algunas propuestas sobre prácticas pedagógicas en la enseñanza del arte que utilizan el proceso de desplazamiento urbano como un impulsor de experiencias sensibles para el estudiante, capaz de despertar una mirada poética sobre la ciudad. . Para esto, el camino metodológico trazado es de naturaleza cualitativa, investigando las percepciones de los estudiantes en la ciudad, materializadas por sus registros poéticos y de imágenes. De esta manera, el enfoque fenomenológico para comprender los datos demostró que la práctica pedagógica referida del desplazamiento urbano permitió acercar y ampliar el contacto de los estudiantes con los diferentes espacios de la ciudad, incitándolos a una mirada sensible y poética con la estructura estética y urbana.

Palabras clave: Art; Enseñanza de arte; Arte como experiencia; Desplazamiento urbano.

\section{Introdução}

A cidade, na concepção de Argan (2014), pode ser compreendida como uma obra de arte, um conjunto de elementos estéticos que compõem um sistema intrinsicamente artístico. Neste contexto, assim como uma obra de arte desperta em seu espectador, a cidade é capaz de evocar naquele que a habita, ocupa e, por ela circula significações, sentimentos, memórias e reminiscências, tornando-a um campo de experiências estéticas, sensoriais e afetivas.

Corroborando com os pressupostos teóricos de Lynch (1997), o indivíduo se comunica e interage com a cidade, mediado por seus elementos físicos constitutivos - as ruas, os bairros, os edifícios e os monumentos - e, a partir destes, organiza, cria e concebe em sua mente uma imagem da cidade, bem como valores culturais, estéticos e éticos. Esta imagem da cidade é dotada de vivências e experiências, as quais o indivíduo protagonizou direta e/ou indiretamente, atribuindo aos elementos que a constituem, significações de ordem pessoal e coletiva. A cidade e seus habitantes, portanto, estabelecem relações indissociáveis em suas dinâmicas. Argan (2014), de modo a investigar as relações e tramas estabelecidas entre o sujeito e objeto, isto é, os habitantes e a cidade, argumenta que essa última não é uma construção em grande escala no espaço, que surge de forma espontânea e instantânea, mas uma construção cuja execução e dinamismo são realizados por indivíduos, os seus habitantes, no decorrer do tempo. Conforme o autor, a “(...) cidade não se funda, se forma” (Argan, 2014). 
Neste prisma, os elementos físicos que compõem a cidade - as ruas, as veredas, as calçadas, os edifícios e os monumentos - não são imutáveis, definitivos e tampouco permanentes, todavia estão suscetíveis às transformações, modificações e intervenções na sua forma, textura, espaço e arquitetura, continuamente. No decorrer de sua história, o tecido urbano de uma cidade vivencia um processo constante de transformações, que se dá por meio de substituição de camadas, na qual “(...) cada geração intervém sucessivamente no tecido preexistente que recebe como herança" (Castriota, 2009). Estas transformações contínuas da malha urbana implicam diretamente na paisagem citadina e, sobretudo, na apreensão desta paisagem pelo indivíduo que habita a cidade. Em outras palavras, o indivíduo ao se deslocar pelas ruas da cidade, ao ocupar os seus diferentes espaços - praças, museus, patrimônios, entre outros - estabelece nestas situações relações com a cidade, a experimenta, a vivencia e dialoga visual e conceitualmente com os seus elementos. Deste modo, as modificações de ordem física e estética realizadas nestes elementos influenciarão na relação entre os sujeitos e os objetos que configuram o espaço citadino e, consequentemente, na construção de sua imagem da cidade. Corroborando com tal concepção, Vilém Flusser (apud Fuão, 2000) propõe pensar a cidade como um campo da existência e da experiência humana, cujos espaços permitem aos indivíduos comunicarem-se entre si e com os elementos que os circundam e, desta forma, a própria cidade torna-se a materialização da vida dinâmica da vida civilizada.

Estas constantes transformações no aspecto físico/estético do espaço citadino, e consequentemente, na paisagem urbana como um todo, refletem diretamente na absorção do ambiente visual da cidade pelo indivíduo que a habita, reverberando na construção de uma imagem da cidade orientada por uma ausência de solidez e concretude a respeito da história, da memória e da identidade da cidade. Esta liquidez presente na paisagem citadina tem como um de seus frutos a falta de identificação do indivíduo para com a história, a memória, a cultura e a identidade do espaço em que ocupa, reside e circula, isto é, a própria cidade. Em seus estudos relativos às transformações do tecido urbano, Rykwert (2004) argumenta acerca das fragilidades com que estas sucessões de camadas exercem sobre a malha urbana, pontuando que gradualmente a “(...) cidade será pobre em lugares que possam servir como guias de orientação e 'pontos de interesse', com características marcantes e facilmente identificáveis para que possam servir como pontos de encontro”.

Diante do exposto, legitima-se a importância no ensino de arte de promover práticas pedagógicas que ampliem o contato do educando com os diferentes espaços da cidade, de modo a compreender a sua construção histórica até a contemporaneidade, fazendo-o refletir sobre questões mnemônicas, identitárias e culturais. Neste espectro, a arte-educação propõe 
ao educando, desvendar o campo do (des)conhecido, assumir um olhar crítico e sensível acerca da cidade e suas especificidades, descobrindo nela, outros modos de ver e ser. $\mathrm{Na}$ busca por este deslocamento de um olhar mecanizado para um olhar alternativo à cidade, o ato de caminhar, de deslocar-se pelas veredas citadinas, torna-se uma estratégia capaz de despertar percepções, sensações, sentimentos, memórias e reminiscências.

O caminhar, portanto, torna-se uma prática sensível e estética, uma costura poética do "eu" com o espaço que "habito", ao passo que o percurso, trajeto estabelecido no processo de caminhar, torna-se uma narrativa poética e visual. Em seus estudos acerca do ato de caminhar como prática estética, Careri (2013) pontua que "o caminhar, mesmo não sendo uma construção física de um espaço, implica uma transformação do lugar e de seus significados, o caminhar produz lugares”. Fundamentado nesses pressupostos teóricos, o espaço, uma vez demarcado com a presença de alguém que o habita e que deixa nele o rastro de um percurso, deixa de ser um território de ausências para assumir-se enquanto lugar, campo de presenças errantes.

Partindo do caminhar como uma ação estética e sensível, este artigo objetiva apresentar algumas proposições acerca de práticas pedagógicas no ensino de artes que se utilizem do processo de deslocamento urbano como propulsor de experiências sensíveis ao educando, capaz de despertar um olhar poético sobre a cidade, ampliando seu campo perceptivo acerca dos espaços e elementos que a compõem. Para isso, o artigo descreverá um procedimento metodológico desenvolvido em uma pesquisa de mestrado realizada no Programa de Pós-Graduação em Ensino, do Instituto Federal de Educação, Ciência e Tecnologia de Mato Grosso, na cidade de Cuiabá1, estado de Mato Grosso, Brasil.

A referida pesquisa, desenvolvida na linha de Ensino de Linguagens e seus códigos, foi aplicada com educandos de uma turma de $3^{\mathrm{a}}$ ano do Ensino Médio, em uma escola estadual. As proposições e reflexões apresentadas neste artigo são resultados de uma oficina realizada com os educandos, tendo como proposta primeira o ato de caminhar pela cidade como prática estética e sensível, de modo a incitar nesses educandos um olhar poético e exploratório pelo espaço citadino e as constantes transfigurações físicas na sua paisagem urbana.

\footnotetext{
${ }^{1}$ O município de Cuiabá configura-se como a capital do Estado do Mato Grosso, Brasil. Fundada em 1719, tem como municípios limítrofes Rosário Oeste, ao Norte, Chapada dos Guimarães, ao Nordeste, Campo Verde, ao Leste, Santo Antônio de Leverger, ao Sul, Várzea Grande, ao Sudoeste, Acorizal, ao Noroeste, e Rondonópolis, ao Sudeste.
} 


\section{Percurso Metodológico}

Com o objetivo de pontuar reflexões acerca de práticas pedagógicas no ensino de arte que se utilizam do deslocamento pela cidade como prática sensível e poética, o presente artigo tem sua natureza metodológica qualitativa, visto que "aprofunda-se no mundo dos significados, das ações e relações humanas, um todo não perceptível e não captável em equações, médias e estatísticas" (Minayo, 2002). Ademais, contempla interpretações de realidades sociais (Bauer \& Gaskell, 2002), a partir de um "enfoque na subjetividade, (...) já que o foco de interesse é justamente a perspectiva dos participantes" (Moreira, 2004).

Conforme referido, compõem este artigo reflexões e apontamentos acerca de dados coletados em um procedimento metodológico, o qual se configura como sendo uma oficina desenvolvida pelo pesquisador com os educandos de uma turma de $3^{\circ}$ ano do Ensino Médio de uma escola estadual, na cidade de Cuiabá, estado de Mato Grosso. A oficina compreende uma aula de campo, na qual os educandos são convidados a caminharem pelo centro histórico da cidade de Cuiabá. Objetiva-se nesta ação, que o educando visualize, perceba e sinta a paisagem citadina, conduzido por um olhar e sentir sensíveis e conscientes acerca da estrutura urbana, apreendendo suas transformações e constâncias no decurso da história. O deslocamento aqui proposto fundamenta-se nos pressupostos teóricos de Gordon Cullen (1993), segundo o qual, o sujeito, ao se deslocar e transitar pelos diferentes espaços da cidade, não está ileso à estrutura e dinâmica citadina, mas as apreendem, as internalizam e as percebem, sendo por elas afetado.

\subsection{Deslocamento e Percepção: a Cidade na Perspectiva de Gordon Cullen}

Conforme Cullen (1993), o deslocamento contempla primordialmente três aspectos referentes às etapas de percepção dos sujeitos ao transitarem pelas ruas, bairros, calçadas e demais vias da cidade. O primeiro aspecto, definido como óptica, corresponde à visão. Neste momento, enquanto o indivíduo caminha no decurso de uma rua, suas percepções configuram-se em sequências, isto é, “(...) primeiro ele avista uma rua, em seguida, entra em um pátio, que sugere um novo ponto de vista de um momento e assim por diante" (Adam, 2008).

Desse modo, ao transitar pelas ruas da cidade, o sujeito é movido por visões sequenciais - denominada como visão serial - que, configuram e estruturam uma sucessão de imagens e acontecimentos acerca dos elementos que compõem a cidade. Ressalta-se que estes 
elementos da cidade os quais se estabelecem frente ao campo de visão do indivíduo, de modo sequencial, exercem sobre ele um impacto de ordem também emocional. Nesta perspectiva, Cullen argumenta que este impacto de caráter emocional/afetivo assume maior intensidade ao o sujeito que se desloca pela cidade e assimila os contrastes presentes na paisagem urbana:

(...) uma rua que se prologa à nossa frente sempre em linha reta tem um impacto relativamente pequeno, porque o panorama inicial é rapidamente assimilado, tornando-o monótono. O cérebro humano reage ao contraste, e é a diferença entre as coisas, e ao ser estimulado simultaneamente por duas imagens - a rua e o pátio apercebe-se da existência de um contraste bem marcado. Neste caso, a cidade torna-se visível num sentido mais profundo; anima-se de vida pelo vigor e dramatismo dos seus contrastes. Quando isto não se verifica ela passa despercebida é uma cidade incaracterística e amorfa (Cullen, 1993).

O segundo fator que orienta o deslocamento do sujeito pela cidade denomina-se local, o qual corresponde às reações e percepções do indivíduo em função de sua posição e localização no espaço. Entre outras palavras, refere-se às percepções do sujeito enquanto este caminha pela cidade e percebe o contraste entre os espaços abertos e os espaços fechados, reações estas designadas por Ibid (1993) como, "estou cá fora", depois, "estou a entrar para dentro", e finalmente, "estou aqui dentro". Esta contraposição espacial entre os ambientes fechados e abertos também reverberam no sujeito um impacto de ordem emocional.

O terceiro aspecto diz respeito ao conteúdo da cidade, isto é, a sua constituição e composição. Por intermédio da visão e da localização, o transeunte é convidado a explorar, captar e assimilar o conteúdo da cidade, ou seja, suas cores, texturas, níveis, escalas, estilos, arquiteturas, e, sobretudo, a própria identidade citadina. Nesta perspectiva, o conteúdo corresponde à natureza e à morfologia da cidade, a forma como ela se constrói e organiza, definindo sua paisagem urbana. O conteúdo, portanto, é capaz de definir e revelar os vestígios, as marcas e a história da cidade, sendo a presença e a ausência destes elementos. Denuncia a preservação dos elementos da cidade, bem como suas transformações e, sobretudo, suas ausências no processo histórico da cidade, marcando os seus desaparecimentos. Neste processo, os três fatores que determinam o deslocamento do sujeito pela cidade - a óptica, o local e o conteúdo da cidade - articulam-se de forma indissociável e determinam a construção da imagem da cidade pelos seus habitantes.

Diante dos pressupostos teóricos de Cullen, ressalta-se que o educando à medida que se desloca pelas ruas do centro histórico, costura no trajeto percorrido, suas percepções, 
sensações e memórias. Seu olhar atento é capaz de atravessar a cidade e por ela ser atravessado, num jogo bilateral, em que um constitui o outro.

\subsection{Fenomenologia da percepção e a prática educadora}

A pesquisa assume como abordagem metodológica para tessitura e compreensão dos dados a Fenomenologia, cuja definição é o estudo das essências, dos fenômenos presentes no mundo, sem antes serem atribuídos a eles valores pré-estabelecidos pela ciência (MerleauPonty, 2006). A Fenomenologia, neste prisma, recorre à ação primeira do ser humano: seu estado de consciência diante dos objetos, suas percepções primordiais e seu estado de subjetividade:

É uma filosofia transcendental que coloca em suspenso, para compreendê-las, as afirmações da atitude natural, mas é também uma filosofia para a qual o mundo sempre esteve 'ali', antes da reflexão, como uma presença inalienável, e cujo esforço todo consiste em reencontrar este contato ingênuo com o mundo, para dar-lhe enfim um estatuto filosófico (Merleau-Ponty, 2006).

Conforme Merleau-Ponty, a unidade fundamental da Fenomenologia está no próprio ser humano, na sua experiência direta com o mundo e na sua vivência primeira. É um contraponto aos significados construídos pela ciência, os quais buscam justificar a decorrência dos fenômenos com base em uma visão de mundo já pré-concebida. A Fenomenologia, portanto, põe em suspenso os fenômenos e os reconstroem, a partir das novas suturas possibilitadas pela percepção pura dos sujeitos. Trata-se de uma psicologia descritiva, a qual considera a experiência humana como fonte primária para entender os fenômenos sociais:

Tudo aquilo que sei do mundo, mesmo por ciência, eu o sei a partir de uma visão minha ou de uma experiência do mundo, sem a qual os símbolos da ciência não poderiam dizer nada. Todo o universo da ciência é construído sobre o mundo vivido, e se quisermos pensar a própria ciência com rigor, apreciar exatamente seu sentido e seu alcance, precisamos primeiramente despertar essa experiência do mundo da qual ela é a expressão segunda. A ciência não é e não terá jamais o mesmo sentido de ser que o mundo percebido, pela simples razão de que ela é uma determinação ou uma explicação dele (Merleau-Ponty, 2006).

Em consonância com os pressupostos teóricos referidos, a Fenomenologia contribui para os estudos dos fenômenos sociais, visto que considera o próprio fenômeno em sua essência, em sua ordem primordial, desvelando e reconstituindo-o, fundamentado no ato 
perceptivo do indivíduo. Em outras palavras, o método fenomenológico descreve o fenômeno, a partir da tomada de consciência e percepção, explorando não somente o campo perceptivo, como também o campo das sensações e da corporalidade.

Considerando que o artigo objetiva apresentar algumas proposições acerca de práticas pedagógicas no ensino de arte que se utilizem do processo de deslocamento urbano como propulsor de experiências sensíveis ao educando, a pesquisa utilizar-se-á do método fenomenológico a fim de descrever e compreender o modo como esta prática errante possibilita ao educando estabelecer relações mnemônicas, identitárias e culturais com o espaço citadino, ampliando, consequentemente, suas experiências sensíveis e estéticas com os elementos que compõem a cidade.

$\mathrm{Na}$ perspectiva de ponderar alguns desdobramentos acerca da prática pedagógica desenvolvida neste estudo - cuja proposição compreende um deslocamento urbano pelo centro histórico da cidade de Cuiabá -, a pesquisa partirá das percepções dos educandos, seus registros escritos e imagéticos, os quais materializam suas sensações diante do campo citadino. As percepções de cada educando serão costuradas, de modo a suturar uma cidade sentida e percebida, ressignificando seus espaços.

\section{Resultados e Discussão}

Conforme referido, o deslocamento pela cidade configurou-se como uma aula de campo, mediada pelo pesquisador e, realizada por meio de oficina com 13 educandos de uma escola estadual na cidade de Cuiabá, estado do Mato Grosso. Os educandos, cuja faixa etária compreendia entre 15 e 17 anos, cursavam o $3^{\circ}$ ano do Ensino Médio e participaram da oficina, mediante a aprovação da escola, bem como a autorização dos responsáveis, consoante ao estipulado pelo Comitê de Ética.

A oficina objetivava que o educando, ao se deslocar pela cidade, visualizasse, percebesse e sentisse a paisagem citadina, conduzido por um olhar e sentir sensíveis e conscientes acerca da estrutura urbana, apreendendo suas transformações e constâncias no decurso do tempo. Para isso, o percurso a ser deslocado e explorado concerne às principais ruas, veredas e avenidas do centro histórico da cidade de Cuiabá. A escolha do centro histórico justifica-se por ser: o ponto zero de uma cidade, a sua matriz primeira. Revela em sua estrutura, as transformações urbanas, as transfigurações físicas, os desenvolvimentos e retrocessos do engendramento citadino. Denuncia o escoamento do tempo e, por conseguinte, presentifica a fugacidade e permanência de seus elementos compositivos. São estes elementos 
- as ruas, os bairros, as calçadas, as praças, os edifícios e os monumentos - que compõem a paisagem urbana da cidade e sua transitoriedade.

O centro histórico é o núcleo no qual se desenvolveu, no decurso do tempo, as esferas política, econômica, cultural e, sobretudo, social da cidade. Evidencia em sua composição o infindável ciclo da vida urbana, abrigando os referenciais do passado da urbe. Corroborando sobre a concepção de centro urbano, argumenta Pesavento (2008):

(...) o centro é o núcleo original, o ponto de partida nodal de uma aglomeração urbana. O centro é, pois, o marco zero de uma cidade, o local onde tudo começou e o seu núcleo de origem. Assim sendo, o centro é um espaço privilegiado no tempo. Parafraseando a frase bíblica, podemos dizer que no princípio era o centro.

Para a descrição e compreensão dos dados, a pesquisa contou como instrumentos de tessitura o caderno de campo do pesquisar e os cadernos de bordo dos educandos. O primeiro é constituído por breves apontamentos e reflexões do pesquisador, os quais materializam suas percepções captadas no processo de deslocamento. Tais apontamentos e reflexões emergem das observações acerca dos gestos, expressões, falas, questionamentos, posicionamentos e, sobretudo, das ausências destes manifestados pelos educandos ao percorrerem as veredas citadinas. Ademais, foi entregue a cada educando um caderno de bordo, de produção artesanal, denominado caderno de memórias para que os educandos registrassem no formato de texto escrito e/ou imagético suas impressões, memórias, percepções e apreensões acerca dos espaços transitados, na perspectiva de descreverem e corporificarem o ver e sentir sobre a cidade. No que concerne a utilização dos cadernos de campo como instrumento para o registro e a compreensão dos dados, fundamenta Triviños (1987) que as anotações de campo por serem entendidas como “(...) todo o processo de coleta e análise de informações, isto é, elas compreenderiam descrições de fenômenos sociais e físicos, explicações levantadas sobre as mesmas e a compreensão da totalidade da situação em estudo".

Uma vez definidos o espaço a ser percorrido e os instrumentos para coleta e compreensão dos dados gerados na oficina, o trajeto iniciara no cume da Igreja de Nossa Senhora do Rosário e São Benedito, no qual era possível visualizar a vista superior da Avenida Tenente Coronel Duarte, via que anteriormente era designada como Córrego da Prainha, sítio de fundamental importância para se compreender os processos de urbanização da cidade de Cuiabá (Siqueira, 2007). No momento antecedente a subida ao cume, no qual situa-se a referida Igreja, bem como algumas casas do período colonial, alguns educandos 
mostravam-se ansiosos, visto que, conforme suas falas, apenas avistavam a Igreja de forma distante e nunca tinham subido ao cume. Ao chegarem no pátio frontal da Igreja, a paisagem da cidade parecia descortinar-se frente aos olhos dos educandos que demonstram uma expressão de surpresa com a imagem que se desvela. Enquanto um grupo, de característica mais curiosa, explora o pátio frontal, na aparente perspectiva de descobrir naquele espaço os enigmas de uma história a eles não contada, outro grupo detém-se na mureta, contemplando a vista da cidade. Entre ditos verbais e não-verbais, apoiados nas muretas, nos corrimões das escadas e nos bancos dispostos, os educandos registravam entre palavras e imagens aquilo que viam, percebiam e sentiam (Figura 1). Neste momento, as palavras e os desenhos materializavam as percepções de uma cidade que embora vista, parecia não ter sido antes observada e sentida. O educando desapropria-se da posição de um mero transeunte, aquela que percorre as ruas da cidade de modo mecânico e sistemático, sem permitir ser por ela afetado, e assume-se enquanto flâneur, o sujeito de olhar instigante que caminha pela cidade de forma descomprometida, em busca de uma experiência visual e sensível com os elementos que a compõem, configurando-se como um leitor da paisagem urbana (Benjamin, 1989).

Posterior ao cume da igreja de Nossa Senhora do Rosário e Capela de São Benedito, o percurso se direcionou à rua dos Bandeirantes, caracterizada pela permanência das fachadas no estilo arquitetônico colonial. Acerca disso, foi elucidado aos educandos o propósito dos movimentos dos bandeirantes, bem como as características do estilo colonial na arte e na arquitetura. Um dos educandos perguntou se as fachadas das casas não poderiam ser "modernizadas". A partir deste questionamento, o pesquisador elucidou sobre processos de tombamento e a importância da preservação dos patrimônios materiais que compõem a cidade. Diante do questionamento do educando, pode-se perceber em sua indagação que a palavra "modernizar" estava encoberta por um significado progressista, correspondendo a necessidade de desenvolver aquela rua da cidade. Em outras palavras, o ato de modernizar utilizado na indagação parece não incluir em seu significado a importância da preservação e permanência da história material da cidade, sendo de profícua importância pontuar estes conceitos no decurso do deslocamento.

Adiante à rua dos Bandeirantes, o trajeto encaminhou-se para três importantes ruas no processo de formação histórica da cidade: as ruas Galdino Pimentel, Rodrigo Franco e Pedro Celestino - respectivamente as pretéritas ruas do Baixo, do Meio e de Cima. Nestes sítios, os educandos foram instigados a refletirem acerca do primeiro polo comercial e social que se constituiu na cidade, durante seu processo de formação inicial (Siqueira, 2007). Enquanto observavam e discutiam sobre os espaços visitados, percebeu-se o olhar curioso dos 
educandos, o qual revelava um possível redescobrimento da cidade e de sua história. Entre as declarações proferidas durante o deslocamento, os educandos afirmavam que as ruas eram muito estreitas e, somada à altura dos edifícios, imprimiam uma sensação de opressão. Ademais, pontuaram que as ruas possuíam muitos edifícios "destruídos", uma evidente referência a ausência de manutenção e preservação dos edifícios históricos, tornando a cidade mais "triste" e "abandonada", conforme relataram.

Figura 1 - Registro dos educandos nos cadernos de memória.

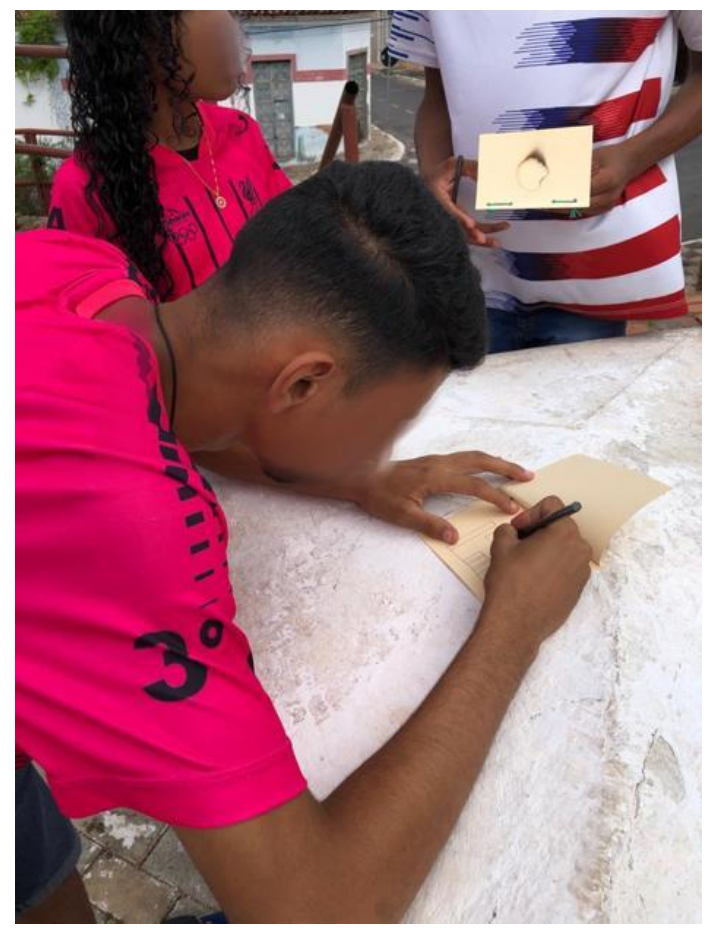

Fonte: acervo do pesquisador.

Seguindo a rua Rodrigo Franco, o percurso direcionou-se à região da Praça da Mandioca, importante ponto nodal, caracterizado pelo aspecto boêmio, em que se desenvolvem as sociabilidades e as manifestações artísticas. Os edifícios desta região apresentam diversas intervenções artísticas no espaço como grafites e pichações, motivo pelo qual os educados concentraram sua atenção e observação. Neste instante, percebeu-se que a cada passo dado, os educandos registravam, por meio da câmera de seus aparelhos celulares, fotografias das edificações que mais lhe despertavam o interesse.

O percurso é finalizado na Praça da República, na qual se situa a Catedral Metropolitana Basílica do Senhor Bom Jesus, primeira igreja erguida na cidade de Cuiabá. Ao passo que se deslocavam pela praça, o pesquisador teceu breves considerações acerca de seu 
(CC BY 4.0) | ISSN 2525-3409 | DOI: http://dx.doi.org/10.33448/rsd-v9i7.4343

surgimento, bem como as transfigurações físicas e estéticas aplicadas aos edifícios ao seu redor, no decurso do tempo. Quando questionados sobre a derrubada da antiga Catedral, de estilo Barroco, para a construção de uma nova, de estilo modernista, os educandos responderam, em sua totalidade, que desconheciam tais transformações, manifestando uma curiosidade para verem fotografias pretéritas da Igreja. Transpassados por um olhar especulativo e curioso, os educandos parecem ter vivenciado o centro histórico, conduzidos por uma sensibilidade. No trajeto percorrido, redescobriram uma cidade ainda não contada, ressignificando e intervindo os espaços ocupados com um ver e ser poéticos, materializados em seus registros sensíveis (Figura 2).

Figura 2 - Registros dos cadernos de memórias dos educandos.

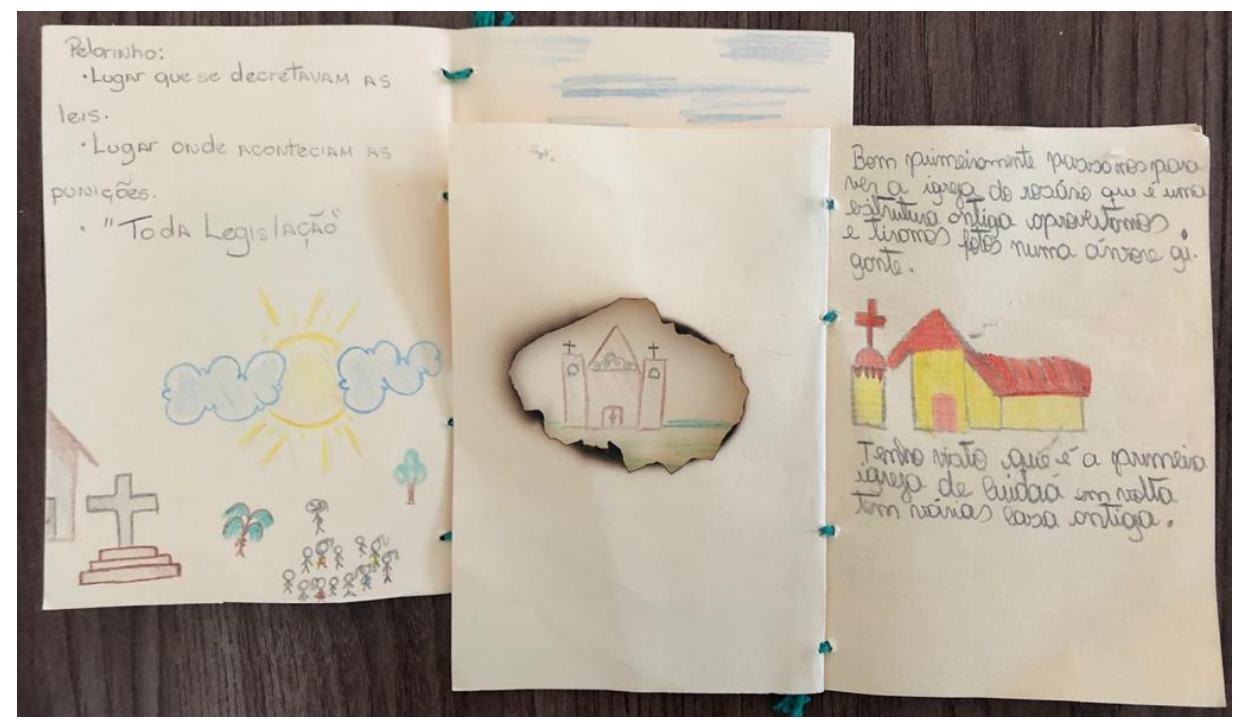

Fonte: acervo do pesquisador.

\section{Considerações Finais}

A paisagem urbana pode ser compreendida como um legítimo proscênio das transformações ocorridas no tecido urbano de uma cidade. Revela as permanências, as constâncias e as perpetuações dos elementos citadinos no decurso do tempo, mas também denunciam essas mesmas transformações, as mudanças, as rupturas, as destruições e os desaparecimentos desses elementos.

Tece na sua estrutura a dialética estabelecida entre a preservação e a destruição, ou na perspectiva de Argan (2010), da relação antitética entre o antigo e o moderno. Estas transfigurações físicas na paisagem urbana reverberam diretamente na construção da imagem 
da cidade pelos indivíduos, reverberando, consequentemente, nas suas relações mnemônicas, históricas, identitárias e culturais com os diferentes espaços. Em virtude disso, ressalta-se a importância do educador em arte propor práticas pedagógicas que incitem o educando a estabelecer um campo de contato com a cidade, despertando nele um olhar sensível para a estrutura citadina, por meio de poéticas visuais.

O deslocamento urbano como prática pedagógica no ensino de arte, conforme proposto neste artigo, possibilitou aos educandos participantes reflexões e proposições de diferentes naturezas e níveis de complexidade, manifestadas por suas falas, posicionamentos e, sobretudo, em seus modos de ver e ser no decurso do deslocamento. Esta cartografia percorrida permitiu aos educandos ressignificar os espaços da cidade, deixando de serem apenas territórios para tornarem-se lugares, conforme corrobora Careri (2013) na sua dialética entre os espaços.

O exercício de olhar cidade - desvestido da banal visão mecânica e sistemática de um transeunte - captando e absorvendo seus nuances, suas especificidades e suas insígnias desloca os educandos da posição de transeunte para a de um flânerie, dotando o espaço citadino de sentidos e, consequentemente, rompendo com uma aparente amnésia urbana. Nessa perspectiva, os educandos ao reconstituírem a cidade, a partir de suas experiências sensíveis, assumem-se enquanto sujeito mnemônico, histórico e social, compreendendo que não é apenas mais um corpo que ocupa o espaço, mas um ser social cujas operações no espaço urbano se desenrolam em um processo bilateral e retroalimentar, no qual a cidade lhe afeta e vice-versa.

Este estado de consciência do educando deriva de suas percepções e sensações na cidade, através de um processo fenomenológico, em que a sensação entre o sujeito e objeto, isto é, entre o educando e os elementos citadinos configuram-se como uma comunhão (Merleau-Ponty, 2006). Tal comunhão ficou evidente no deslocamento urbano como prática pedagógica, uma vez que os educandos revelaram em suas falas, seus apontamentos e seus registros poéticos um novo olhar acerca da cidade, carregado de descobertas, curiosidades e, anseios, que outrora se faziam ausentes. Uma cidade não mais vista, mas percebida pelos educandos.

Conclui-se que a prática de deslocamento urbano enquanto proposta pedagógica no ensino de arte contemplou o objetivo apresentado neste artigo, visto que os educandos ao caminharem pelos diferentes espaços citadinos, ao percorrerem as veredas que materializam a história e a memória cuiabana, repensaram seu modo de ver e ser na cidade, construindo um pensamento crítico e estético acerca das relações entre espaço-tempo, e exercitaram um olhar 
sensível e poético para os elementos que compõem o espaço urbano, de modo a perceberem a cidade como uma obra de arte, conforme propôs Argan (2014).

\section{Referências}

Adam RS. (2008). Analisando o conceito de paisagem urbana de Gordon Cullen. Da Vinci. 5 (1), 61-8.

Argan GC. (2014). História da Arte como História da Cidade. São Paulo: Martins Fontes.

Barbosa AM \& Cunha FP. (2010). Abordagem triangular no ensino das artes e culturas visuais. São Paulo: Cortez.

Barbosa, A. M. \& Amaral, L. (2008). Interterritorialidade: mídias, contextos e educação. São Paulo: Editora Senac São Paulo.

Bauman Z. (2005). Identidade. Rio de Janeiro: Zahar.

Bauer MW \& Gaskell G. (2002). Pesquisa qualitativa com texto, imagem e som: um manual prático. Petrópolis: Editora Vozes.

Benjamin W. (1989). Obras Escolhidas III: Charles Baudelaire, um lírico no auge do capitalismo. São Paulo: Editora Brasiliense.

Careri F. (2013). Walkscapes: o caminhar como prática estética. São Paulo: Editora G. Gili.

Castriota LB. (2009). Patrimônio Cultural: Conceitos, políticas e instrumentos. São Paulo: Annablume.

Cullen G. (2006). Paisagem Urbana. Lisboa: Martins Fontes.

Fuão FF. (2000). Cidades Fantasmas. ARQTEXTO. 1 (1) 12-23.

Lynch K. (1999). A Imagem da Cidade. Lisboa: Martins Fontes. 
Pesavento SJ. (2008). Memória, história e centralidade urbana. Mosaico. Revista de História do Programa de Pós-graduação em História da Pontifícia Universidade Católica de Goiás. 1 (1) 3-12.

Martins J. (1992). Um enfoque fenomenológico do currículo: Educação como poíeses. São Paulo: Editora Cortez.

Merleau-Ponty M. (2006). Fenomenologia da percepção. São Paulo: Martins Fontes.

Meira SM. (2018). Patrimônio e Escola: o Centro Histórico de Cuiabá e as práticas educativas no ensino de história. Dissertação de mestrado. Programa de Pós-graduação Profissional em Ensino de História. Universidade Federal do Mato Grosso.

Minayo MCL. (2001) Pesquisa social: teoria, método e criatividade. Petrópolis: Vozes.

Rykwert J. (2004). A Sedução do Lugar: a história e o futuro da cidade. São Paulo: Martins Fontes.

Siqueira EM et al. (2007). Cuiabá: de vila a metrópole nascente. Cuiabá: Entrelinhas Editora.

\section{Porcentagem de contribuição de cada autor no manuscrito}

$$
\begin{gathered}
\text { Rafael Branco da Silveira - 50\% } \\
\text { Imara Pizzato Quadros - 25\% }
\end{gathered}
$$

Claudia Lucia Landgraf Pereira Valerio da Silva - 25\% 